Original article

\title{
Study on age of menarche between generations and the factors associated with it
}

\author{
Balaji Ramraj, V. Meenakshi Subramanian, Vijayakrishnan G \\ Department Of Community Medicine, SRM Medical College Hospital and Research Centre, SRM Institute Of Science And Technology, Chengalpattu, 603203, Tamilnadu, \\ India
}

\section{A R T I C L E I N F O}

\section{Keywords:}

Age of menarche

Decline in menarcheal age

Menarcheal pattern between generations

\begin{abstract}
A B S T R A C T
Background: A declining trend of menarcheal age is noted in many developing and developed countries since last century. There is a reduction in the age of menarche by nearly one month per decade suggesting a secular decline in age of menarche among Indian women.

Aim: To find out the mean age of menarche in the adolescent girls and their mothers and to know the factors associated with the change in the mean age of menarche.

Methodology: A comparative cross-sectional study was conducted in SRM field practice area, Mamandur involving100 adolescent girls and their mothers using a semistructured questionnaire. Descriptive statistics and chi square analysis, univariate and multivariate analysis were used to analyse the data. A value of $\mathrm{p}<0.05$ is considered significant.

Results: The mean age of menarche in adolescent girls is $12.5( \pm 1.42)$ years and their mother is $14( \pm 1.10)$ years. The study revealed that in menstrual history, age of menarche, regularity, menstrual flow and habitual and lifestyle factors like outside food consumption, sedentary/active lifestyle, sleep, dietary habits, polycystic ovary syndrome (PCOS) showed significant difference between adolescent girls and their mother. In univariate analysis outside food consumption, sedentary lifestyle and hours of activity were found significant. In multivariate analysis sedentary lifestyle was only found to be significant for early menarche.

Conclusion: A decline in the mean age of menarche was found among adolescent girls compared to their mothers. The adolescent girls attained menarche early compared to their mothers and this difference was attributed to sedentary lifestyle.
\end{abstract}

\section{Introduction}

A secular declining trend in the age of menarche has been reported in most of the developed and developing countries since the beginning of 20th century across the globe. ${ }^{1}$ Many studies were conducted to track this decline in the recent times. Recent study by Population Association of America noted a significant decline in the age at menarche worldwidewhich was observedirrespective of socioeconomic status, race or ethnicity. A downward trend from $>16$ years in the mid-1800s to $<13$ years by the 1980s was reported. ${ }^{2}$

Studies also documented the trend towards earlier menarche in England, ${ }^{3}$ Israel $^{4}$, China, ${ }^{5,6}$ India $^{7}$, Korea8], Ghana ${ }^{8}$, Mexico, ${ }^{9}$ Thailand $^{10}$ the USA. ${ }^{11,12}$

Results of the study showed that in Europe, the menarcheal age decreased from 16 to 17 years in the mid-19th century to 13 years in the mid-20th century, ${ }^{13}$ and among the Chinese girls the age at menarche declined from 14.25 in girls born before 1976 to 12.60 in girls born after 2000 , with an estimated decline of 0.51 years per decade. ${ }^{5}$ A decline in age of menarche was also reported in 20th centuryin several countries such as Canada, Japan, Taiwan, Russia, Turkey, and Indonesia. ${ }^{9}$ A similarstudy showed that average age of menarche in India was 14 years in $1955^{13}$ and evidence from Indian Human Development survey showed that there has been a reduction in age of menarche by nearly one month per decade suggesting of secular decline in age of menarche among Indian women. ${ }^{7}$ A study conducted in west Bengal showed that the mean age of menarche is 12.8 years ${ }^{14}$ and another study conducted in urban area of south India in 2018 showed that mean age of menarche is 13 years. ${ }^{15}$

This secular declining trend of menarcheal age is known to cause many health problems in women. Early menarche is known to be at a

\footnotetext{
* Corresponding author.

E-mail addresses: arbee2002@gmail.com (B. Ramraj), vmeenakshi2100@gmail.com (V.M. Subramanian), vijayakg@srmist.edu.in (V. G).
} 
greater risk of psychosocial as well as physical health problems in women. This includes delinquency, risky sexual behaviour, obesity, diabetes, cardiovascular disease, and breast cancer. ${ }^{16}$ Thus, it is important to look into the factors which influence this decline in the age of menarche.

It is known that genetic, nutritional status, area of residence, geographic region, and linguistic groups, racial, climatic and cultural background, socio-economic status, have an influence over the menarche age ${ }^{17}$ From reported studies it was noted that girls with a higher BMI (overweight and obesity) attained menarche early compared than those without excess weight. ${ }^{5,18}$ Girls from urban areas, high socio income families attained menarche earlier than the girls from poor socio-economic status ${ }^{8}$ and girls from urban areas attained menarche earlier compared to the girls in rural area. ${ }^{5}$

Most of the studies were on the association of the age of menarche with nutritional status, BMI, residence region, socio-economic status, geographical location. Very few studies were reported in the aspect of association between menarche and the environmental changes, lifestyle patterns, among which most of them are foreign studies. During the past decades there has been a significant change in the way of living. This includes change in traditional and cultural practices like food habits, free time activities, sleep and work patterns, lifestyle pattern, habits and adoption of modern lifestyle. This can be attributed to the drastic increase in the population, increased physiological stress, rapid urbanization and industrialization. Keeping in view of the limited scope of the reported studies, present study on influence of lifestyle patterns and habits of the individual over the menarcheal age in the Indian background was conducted. Moreover, no recent studies related to comparative mean age pattern of the mother and daughter i. e over the generations and the factors which varied and influenced the menarcheal age pattern over the years was reported. With this background the present study was conducted with the following objectives to find out the mean age of menarche in the adolescent girls and their mothers and to enumerate the lifestyle and habitual factors associated with the change in the mean age of menarche.

\section{Methodology}

A population based Analytical cross-sectional study was conducted with a sample size 200 estimated using the study "Age of menarche in Indian women" where it was observed that the most of the women attained menarche at the age of 14 and 13 years with a prevalence of $57 \%$. Thus the value $\mathrm{P}$ was taken as 57 with $20 \%$ as relative precision and $20 \%$ as non-response rate. The sample size thus obtained was 90 (rounding off to 100). Two groups namely A and B was framed with 100 participants each. Group A consists of 100 adolescent girls and group B consists of their mother (100), so as to establish an equal distribution of participants between the generations-mother and adolescent girls. The ethical and scientific committee clearance was obtained.

The selection of the study was done using simple random sampling. The sampling frame was created using family folders for the areas which was availed from the respective PHC. From them adolescent girls who attained menarche were sorted out and among them sampling was done by Simple random sampling method (lottery). Data was collected between September and October in SRM field practice areas among adolescent girls and their mothers. The adolescent girls from SRM field practice areas and their mothers were selected in order to eliminate the environmental and genetic impact over the results obtained. Adolescent girls who attained menarche and where both mother and daughter were willing to participate in the study were only included. Those who were not willing or where only either only one of them were willing to participate or when either one of them were not available due to certain circumstances, were excluded from the study.

Respondents were appraised about the study and written consent were obtained from both adolescent girls and their mothers. Data was collected by interviewer through a semi-structured pre-tested questionnaire. Adolescent girls and their mothers were interviewed individually one after the other and also separately. When mothers were interviewed it was clearly explained to them to answer the questions based on the events and activities during their adolescent period of life and not according to their present lifestyle. All of them remembered their adolescent period of life and reported it accordingly, as most of the questions were about their way of living and lifestyle. The questionnaire included questions on socio-demographic characteristic of study population, lifestyle, menstrual and medical history. Responsesrelated to food habits, stress levels, physical activity, sleep pattern, mood swingsetc were obtained under lifestyle details taken up for the study.

Data was entered on excel sheet Microsoft Excel spread sheet and analysed using SPSS software 2.0 version. Data was analysed by descriptive statistics, Chi-square. Lifestyle and habitual factors influencing the menarcheal age were subjected to Univariate logistic analysis following which multiple logistic regression was applied, with the decrease in the menarcheal age as the dependent variable and the lifestyle and habitual factors as independent variable. $P$-value $<0.05$ was considered to be statistically significant for all analyses.

\section{Results}

200 participants were divided into two groups namely, as group A and $B$ in which 100 were adolescent girls and 100 were their mother respectively. The mean age of the participants in the group A and B were $17.5( \pm 3.05)$ and $42.61( \pm 3.51)$ respectively. The mean BMI of group A and $B$ were 26.34 and 27.7 respectively.

\subsection{Comparision between the mean age of menarche in adolescent girls and their mothers}

The mean age of menarche in group A i.e. adolescent girls was 12.5 $( \pm 1.42)$ years and the mean age of menarche for their mother was 14 $( \pm 1.10)$ years. The median for the group A and B was 12 and 14 years respectively. Among the 100 responses of the adolescent girls it was seen that one percent attained menarche at 9 years of age, $7 \%$ attained menarche at 10 years, $16 \%$ attained menarche at 11 years of age, $29 \%$ attained menarche at 12 years which was the age group where maximum number of participants attained menarche, followed by 13 years where $24 \%$ attained menarche. $16 \%$ of respondents from group A attained menarche at 14 years of age group, six percent attained menarche at 15 years of age group and two percent attained menarche at 16 years. Whereas, the youngest age group of menarche was seen among the mother is 10 years with one percent, six percent at 12 years age group, $33 \%$ at 13 years of age group where maximum number of participants attained menarche, followed by $32 \%$ in 14 years of age group, $22 \%$ attained menarche at 15 years of age group, five percent in 16 years and one percent in 17 years age group.

It was seen that the distribution of the age of menarche in case of daughter was highest in the earlier period of life and declined towards the later period compared to their mothers where the distribution of the age of menarche was lowest at the earlier period of life and it increased at the later periods.

\subsection{Comparision of the menstruation history, lifestyle and habitual factors among the adolescent girls and their mothers}

Statistically significant difference in the menstruation history among adolescent girls and their mother was seen. $92 \%$ of the adolescent girls who attained menarche were between the age interval of 10-12 years and $13-15$ years with an equal distribution of $46 \%$ in each interval $\left(\chi^{2}\right.$ ${ }^{4} \mathbf{4 4 . 2 1 , p}=\mathbf{0 . 0 0 0 1}$ ). Whereas, $89 \%$ of their mothers attained menarche in the age interval of 13-15 yrs. Menstrual cycle was found regular in the mothers $(92 \%)$ compared to the adolescent girls $(63 \%)\left(\chi^{2}\right.$ $=\mathbf{2 4 . 1 1}, \mathbf{p}=\mathbf{0 . 0 0 0 1 *})$. It was seen from the above table that adolescent girls were consuming more junk and fast food whereas their mothers 
reported that they never consumed junk (packed foods) or fast foods during their adolescent periods as such products were very rarely available during their period $\left(\chi^{2}=103.03, p=0.0001 *\right)$.

It was also seen that sedentary type of lifestyle was followed by $73 \%$ of adolescent girls where as $100 \%$ of their mothers led an active lifestyle $\left(\chi^{2}=\mathbf{1 1 4 . 9 6}, \mathbf{p}=\mathbf{0 . 0 0 0 1 *}\right)$. Adolescent girls spent their leisure time on electronic gadgets (watching TV, mobile phones), reading books, whereas only few reported playing outdoor games and in household activities. The study revealed that about $70 \%$ of adolescent girls spent $>4 \mathrm{~h}$ on their mobile phones. Only $20 \%$ of girls reported to play outdoor games, seven percent of girls reported to spend their time in household activities. It was also revealed that all adolescent girls spent at least $4 \mathrm{~h}$ in a day on electronic gadgets which were not there during the period of their mothers. It was reported that their mothers spent their time in playing out door games and household activities.

It was noted from Table 1 that there was no significant difference in the frequency of non-veg consumption by the adolescent girls and their mothers $\left(\chi^{2}=\mathbf{8 . 0 6}, \mathrm{p}=\mathbf{0 . 3 2 7 ^ { * }}\right)$, only a slight variation was noted in the non-veg consumption pattern between both the groups. The prevalence of PCOS was more in adolescent girls (18\%) compared to their mothers $(3 \%)$ making it significant $\left(\chi^{2}=\mathbf{1 1 . 9 7 1 3}, \mathrm{p}=\mathbf{0 . 0 0 0 5 4}\right)$.

Therefore, from Table 1 it can be inferred that in menstruation history there was a significant difference among adolescent girls and their daughter in factors like age of menarche, flow, regularity.

In terms of habitual factors and lifestyle a significant difference was noted in terms of outside food consumption, active/sedentary lifestyle,

Table 1

Comparison of menstruation history, lifestyle and habitual factors among adolescent girls and their mother.

\begin{tabular}{|c|c|c|c|c|}
\hline Variables & Subgroup & $\begin{array}{l}\text { Mother } \\
(\%)\end{array}$ & $\begin{array}{l}\text { Adolescent } \\
\text { girls (\%) }\end{array}$ & $\begin{array}{l}\text { Statistical } \\
\text { significance }\end{array}$ \\
\hline & & $\mathrm{N}=100$ & $\mathrm{~N}=100$ & \\
\hline \multirow{5}{*}{$\begin{array}{l}\text { 1) AGE OF } \\
\text { MENARCHE }\end{array}$} & 7-9 yrs & 0 & 1 & \\
\hline & & & & \\
\hline & $10-12$ yrs & 7 & 46 & $\chi^{2}=44.21$ \\
\hline & $13-15$ yrs & 89 & 46 & df -3 \\
\hline & $16-18$ yrs & 4 & 7 & $\mathrm{p}=0.0001 *$ \\
\hline \multirow[t]{2}{*}{ 2) REGULARITY } & Regular & 92 & 63 & $\begin{array}{l}\chi^{2}=24.11, \text { df }- \\
1\end{array}$ \\
\hline & Irregular & 8 & 37 & $\mathrm{p}=0.0001 *$ \\
\hline \multirow[t]{3}{*}{ 3) FLOW } & Minimal & 93 & 10 & $\chi^{2}=138.85$ \\
\hline & Normal & 7 & 59 & df - 2 \\
\hline & Heavy & 0 & 31 & $\mathrm{p}=0.0001^{*}$ \\
\hline \multirow[t]{2}{*}{ 4) OUTSIDE FOOD } & $\begin{array}{l}<1 \text { days/ } \\
\text { week }\end{array}$ & 68 & 0 & $\begin{array}{l}\chi^{2}=103.03, \mathrm{df} \\
-1\end{array}$ \\
\hline & $\begin{array}{l}\text { 1-4 days/ } \\
\text { week }\end{array}$ & 32 & 100 & $\mathrm{p}=0.0001^{*}$ \\
\hline \multirow[t]{2}{*}{ 5) FREE TIME } & Active & 100 & 27 & $\begin{array}{l}\chi^{2}=114.96, \mathrm{df} \\
-1\end{array}$ \\
\hline & Sedentary & 0 & 73 & $\mathrm{p}=0.0001 *$ \\
\hline \multirow[t]{2}{*}{ 6) SLEEP } & $<6 \mathrm{~h}$ & 5 & 0 & $\begin{array}{l}\text { Fisher exact } \\
\text { probability - } \\
5.13 \text {, df - } 1\end{array}$ \\
\hline & $\geq 6 \mathrm{~h}$ & 95 & 100 & $0.03^{*}$ \\
\hline \multirow{8}{*}{$\begin{array}{l}\text { 7) CONSUMPTION } \\
\text { OF NON-VEG } \\
\text { DAYS/WEEK }\end{array}$} & 0 & 12 & 11 & \\
\hline & 1 & 6 & 4 & \\
\hline & 2 & 17 & 8 & \\
\hline & 3 & 13 & 10 & $\chi^{2}=8.06, \mathrm{df}-7$ \\
\hline & 4 & 14 & 13 & $\mathbf{p}=0.327^{*}$ \\
\hline & 5 & 20 & 25 & \\
\hline & 6 & 8 & 9 & \\
\hline & 7 & 10 & 20 & \\
\hline \multirow[t]{2}{*}{ 8) PCOS } & Present & 3 & 18 & $\begin{array}{l}\chi^{2}=11.9713 \\
\text { df }-1\end{array}$ \\
\hline & Absent & 97 & 82 & $\mathrm{p}=0.00054^{*}$ \\
\hline
\end{tabular}

sleep, and PCOS factors.

\subsection{Relation between the lifestyle and habitual pattern on the menarcheal age}

From the distribution pattern in the age of menarche in the line graph 1 it is noted that the mean age of menarche adolescent girls was 12.5 whereas for their mothers it was 14 years. Thus, there is a decline in the trend of menarcheal age. Since our objective is to determine the factors influencing the change in this trend, the mean menarcheal age of mothers i.e. 14 years was considered for comparing the lifestyle and habitual factors influencing the change.

From the results presented in Table 2 it can be inferred that there was a significant impact of consumption of outside food over the change in the menarcheal age pattern $\left(\chi^{2}=12.736, p=0.0001 *\right)$. Those who consumed outside food (junk, packeted fast food) $<1$ day/week attained menarche at $\geq 14$ years of age compared to those who consumed for $1-4$ days/week (see Table 3).

Individuals who had a sedentary type of lifestyle attained menarche early compared to those who had an active lifestyle $\left(\chi^{2}=\mathbf{1 8 . 1 5 8}, \mathrm{p}=\right.$ $\mathbf{0 . 0 0 0 1 *}$ ). Similar to this menarcheal age for those who had longer hours of activity is more compared to those who had lesser activity period in a day $\left(\chi^{2}=7.435, p=0.005^{*}\right)$.

Hours of sleep and the stress level didn't seem to have a significant impact on the menarcheal age. Non-veg consumption pattern also did not seem to have an impact on the menarcheal age. Thus it can be inferred from Table 2 that outside food consumption, lifestyle and hours of activity had a significance in the change of menarcheal age pattern.

Multivariate logistic regression analysis was carried on the three factors namely, outside food consumption, hours of activity, lifestyle pattern which showed significant influence on the change of the menarcheal age pattern. From the result it was inferred that lifestyle pattern had a significant influence over the change of the menarcheal age pattern. The individuals who had a sedentary lifestyle pattern attained menarche earlier compared to those of who had active lifestyle pattern.

\section{Discussion}

The mean age of menarche adolescent girls was $12.5( \pm 1.42)$ years and the mean age of menarche for their mother was $14( \pm 1.10)$ years. The average menarcheal age had decreased by 1.5 years between the generations. Similar finding was reported in the study conductedby Pathak PK et al. on "Secular Trends in Menarcheal Age in India-Evidence from the Indian Human Development Survey" where a secular decline of a month per decade in the age of menarche was found. ${ }^{7}$ The finding of the study revealed that mean age of menarche in the adolescent girls was decreased compared to the mothers and it was also noted that menstrual cycles are regular in mother compared to their daughters. There was a significant difference in the habitual and lifestyle pattern among mother and adolescent girls. It was found in the study that lifestyle pattern whether active or sedentary plays a significant role in the decline of the menarcheal age pattern. Sedentary lifestyle is a type of lifestyle involving little or no physical activity where the person is often sitting or lying down while engaged in activities like reading, socializing, watching television, playing video games or using mobile phone/computer. It is seen that now a days most of the teenage/adolescent individuals spend their leisure time in sedentary works rather than physical activity. This is mostly attributed to the industrialization and improvement of technology in the past few decades, e.g. - most of the activities that humans used to perform manually using energy has been replaced by machines and modern equipment like washing machine for washing clothes, vehicles for travelling, vacuum cleaner, video games etc. thus there has been reduction in the physical activity leading to a sedentary lifestyle and decrease in the time spent on the activity in a day. Due to which abundant leisure time is found which in turn is spent on 


\section{LINE GRAPH 1: AGE OF MENARCHE BY MOTHER AND DAUGHTER}

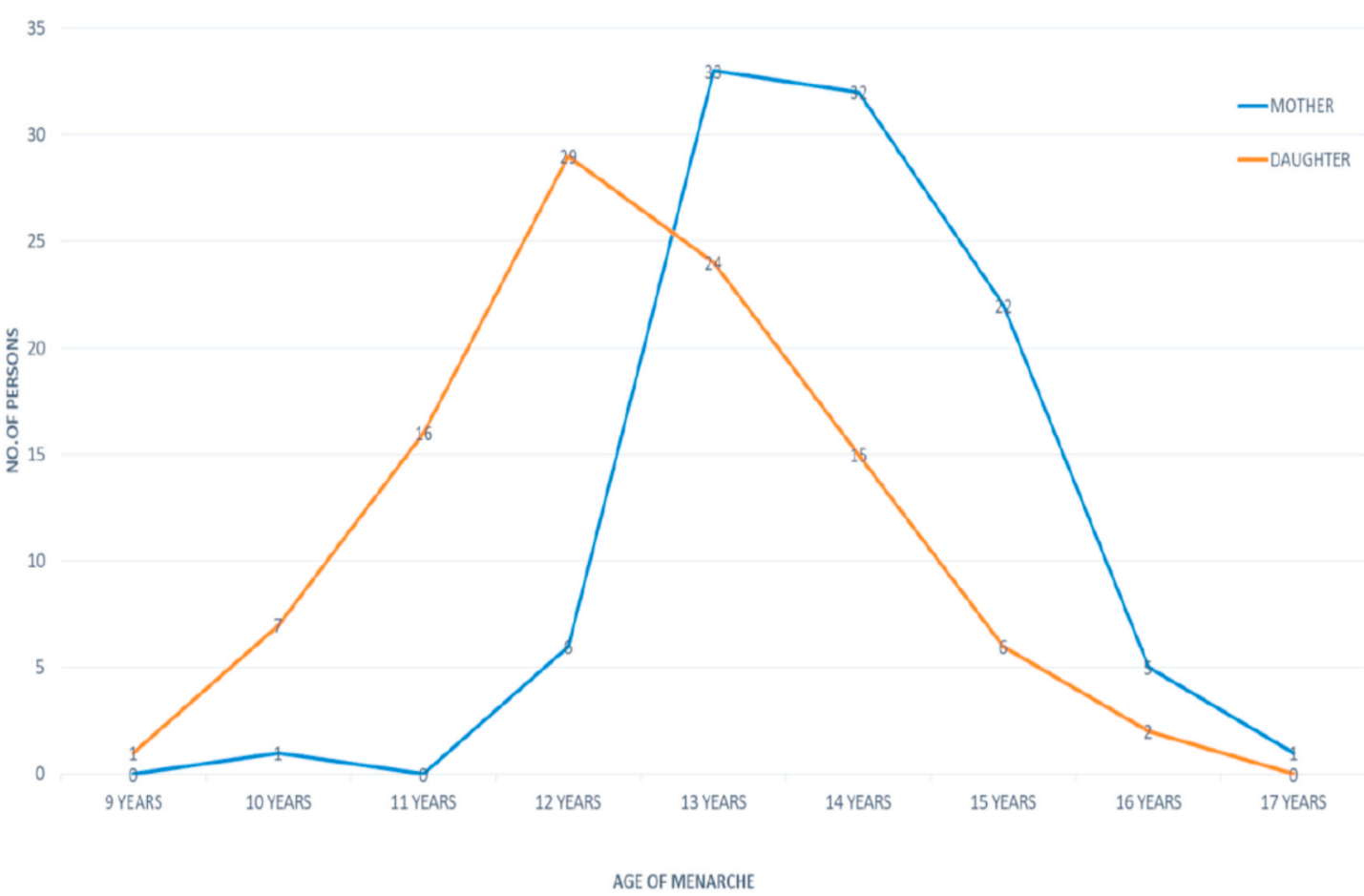

Line graph 1. Menarcheal pattern of group A and B by Age.

Table 2

Univariate analysis of the lifestyle and habitual factors influencing the change in the menarcheal pattern.

\begin{tabular}{|c|c|c|c|c|}
\hline Variables & $\begin{array}{l}\text { Below } \\
14\end{array}$ & $\begin{array}{l}14 \text { and } \\
\text { above }\end{array}$ & $\begin{array}{l}\text { Chi-square } \\
\left(\chi^{2}\right)\end{array}$ & $P$ value \\
\hline \multicolumn{5}{|l|}{$\begin{array}{l}\text { 1) Outside food } \\
\text { consumption }\end{array}$} \\
\hline < 1 Day/Week & 28 & 40 & 12.736 & $0.0001^{*}$ \\
\hline 1-4 Days/Week & 89 & 43 & df -1 & \\
\hline \multicolumn{5}{|l|}{ 2) Lifestyle } \\
\hline Active & 60 & 67 & 18.158 & $0.0001 *$ \\
\hline Sedentary & 57 & 16 & df -1 & \\
\hline \multicolumn{5}{|l|}{ 3) Hours of activity } \\
\hline$<10 h$ & 31 & 9 & 7.435 & $0.005^{*}$ \\
\hline$\geq 10 \mathrm{~h}$ & 86 & 74 & $\mathrm{df}-1$ & \\
\hline 4) Hours of sleep & & & (Fishers) & \\
\hline$<6 \mathrm{~h}$ & 4 & 1 & 0.976 & 0.309 \\
\hline$\geq 6 \mathrm{~h}$ & 113 & 82 & $\mathrm{df}-1$ & \\
\hline 5) Stress & & & (Fishers) & \\
\hline Present & 2 & 1 & 0.084 & 0.627 \\
\hline Absent & 115 & 82 & df -1 & \\
\hline \multicolumn{5}{|l|}{$\begin{array}{l}\text { 6) Veg/non veg } \\
\text { consumption }\end{array}$} \\
\hline$\leq 3$ days/week & 44 & 37 & 0.381 & 0.199 \\
\hline >3 days/week & 73 & 46 & df - 1 & \\
\hline
\end{tabular}

Table 3

Multivariate analysis of the lifestyle and habitual factors influencing the change in the menarcheal pattern.

\begin{tabular}{lllll}
\hline Parameters & B & SE & Exp (B) & P value \\
\hline Outside food consumption & -0.499 & 0.362 & 0.607 & 0.168 \\
Lifestyle & -1.006 & 0.417 & 0.366 & 0.016 \\
Hrs of activity & 0.272 & 0.480 & 1.313 & 0.571 \\
\hline
\end{tabular}

mobiles, television. Physical activity reduces endogenous oestrogen but only few studies have assessed effects on oestrogen metabolism and among them studies which evaluated sedentary behaviour in relation to oestrogen metabolism are very rare. One such study "Association of Active and Sedentary Behaviors with Postmenopausal Estrogen Metabolism" showed that increased activity led to high metabolism and excretion of the oestrogen with lower endogenous oestrogen level whereas sedentary lifestyle that is decrease in activity decreases the metabolism and excretion of the oestrogen thus leading to high level of endogenous oestrogen. ${ }^{17}$ It is known that oestrogen hormone plays a major role in onset of puberty and menarche as the first menstruation is anovulatory (oestrogen break through bleeding). Thus increased concentration of the oestrogen may lead to early menarche and precocious puberty. It is well known fact that sedentary lifestyle leads to increase in BMI, which is one of the risk factor of early menarche. Therefore more studies, ideally prospective and interventional has to be conducted on the influence of active and sedentary lifestyle on oestrogen metabolism, elucidating the mechanism leading to the early menarche.

In conclusion, the present study reveals that the mean age of menarche adolescent girls was $12.5( \pm 1.42)$ years and the mean age of menarche for their mother was $14( \pm 1.10)$ years. The average menarcheal age had decreased by 1.5 years between the generations. It was found that; lifestyle pattern had a significant influence over the change of the menarcheal age pattern. The individuals who had a sedentary lifestyle pattern attained menarche earlier compared to those of who had active lifestyle pattern. Precocious puberty is becoming a problem of public health concern across the globe. More studies such as the present study, focussing on the epidemiological data to find out the magnitude of the problem and risk factors associated with attaining early menarche would be greatly useful. More health programmes meant to increase the knowledge and awareness regarding risk factors, healthy habits to avoid precocious puberty have to be put in place. 


\section{References}

1 Cabanes A, Ascunce N, Vidal E. Decline in age at menarche among Spanish women born from 1925 to 1962. BMC Publ Health. 2009;9:449. https://doi.org/10.1186/ 1471-2458-9-449. This article is available from: http://www.biomedcentral.com /1471-2458/9/449.

2 Onland-Moret NC, Peeters PH, van Gils CH, et al. Age at menarche in relation to adult height: the EPIC study. Am J Epidemiol. 2005;162:623-632.

3 OkashaM, McCarron P, McEwen J, Smith GD. Age at menarche: secular trends and association with adult anthropometric measures. Ann Hum Biol. 2001;28:68-78.

4 Chodick G, Huerta M, Balicer RD, Davidovitch N, Grotto I. Secular trends in age at menarche, smoking, and oral contraceptive use among Israeli girls. Prev Chronic Dis. 2005;2:A12.

5 Meng X, Li S, Duan W, et al. Secular trend of age at menarche in Chinese adolescents born from 1973 to 2004. Pediatrics. 2017;140(2), e20170085. https://doi.org/ 10.1542/peds.2017-0085.

6 Huen KF, Leung SS, Lau JT, Cheung AY, Leung NK, Chiu MC. Secular trend in the sexual maturation of southern Chinese girls. ActaPaediatr. 1997;86:1121-1124.

7 Pathak PK, Tripathi N, Subramanian SV. Secular trends in menarcheal age in Indiaevidence from the Indian human development survey. PloS One. 2014;9(11), e111027. https://doi.org/10.1371/journal.pone.0111027.

8 Ameade EPK, Garti HA. Age at menarche and factors that influence it: a study among female university students in tamale, northern Ghana. PloS One. 2016;11(5), e0155310. https://doi.org/10.1371/journal.pone.0155310.
9 MarvanML,Catillo-Lopez RL Et al The Decreasing Age at Menarche in Mexico 2016 North American Society for Pediatric and Adolescent Gynecology. Published by Elsevier Inc .https://doi.org/10.1016/j.jpag.2016.02.006.

10 Noipayak P, Rawdaree P, Supawattanabodee B, et al. Factors associated with early age at menarche among Thai adolescents in Bangkok: a cross-sectional study. BMC Wom Health. 2017;17:16. https://doi.org/10.1186/s12905-017-0371-5.

11 Wyshak G. Secular changes in age at menarche in a sample of US women. Ann Hum Biol. 1983;10:75-77.

12 Nichols HB, Trentham-Dietz A, Hampton JM, et al. From menarche to menopause: trends among US Women born from 1912 to 1969. Am J Epidemiol. 2006;164: 1003-1011.

13 Peters H, Shrikande SM. Age at menarche in Indian women. Fertil Steril. 1957 JulAug;8(4):355-361. https://doi.org/10.1016/s0015-0282(16)32765-0.

14 Sanyal S, Ray S. Variation in the menstrual characteristics in adolescents of West Bengal. Singap Med J. 2008;49(7):542.

15 Omidvar S, Amiri FN, Bakhtiari A, Begum K. A study on menstruation of Indian adolescent girls in an urban area of South India. J Fam Med Prim Care. 2018;7: 698-702.

16 Yoo JH. Effects of early menarche on physical and psychosocial health problems in adolescent girls and adult women. Korean J Pediatr. 2016;59(9):355-361. https:// doi.org/10.3345/kjp.2016.59.9.355.

17 Dallal CM, Brinton LA. Association of active and sedentary Behaviors with postmenopausal estrogen metabolism. Med Sci Sports Exerc. 2016 March;48(3): 439-448. https://doi.org/10.1249/MSS.0000000000000790.

18 Shaw W, Howkins J, Hudson CN. Shaw's Textbook of Operative Gynaecology. Edinburgh: Churchill Livingstone; 1977. 